\title{
Gıda ve Beslenme Okuryazarlığı
}

\author{
Nazan AKTAŞ ${ }^{1 *}$, Yahya ÖZDoĞAN ${ }^{1}$ \\ ${ }^{1}$ Selçuk Üniversitesi, Sağlık Bilimleri Fakültesi, Beslenme ve Diyetetik Bölümü, Konya \\ *Sorumlu yazar: naktas@selcuk.edu.tr
}

Öz

Bu çalışmada, gıda ve beslenme okuryazarlığı kavramı, tanımı, amacı, gerekli beceriler ve işaret eden bazı unsurların incelenmesi ayrıca bu terim için bir tanım önerilerek ulusal literatüre katkı sağlanması amaçlanmıştır. Bu derleme çalışmada, benzer konuda yapılmış birincil araştırmalardan ortaya çıkan ikincil veriler kullanılmıştır. Gıda ve beslenme okuryazarlı̆ı, gıda ve beslenme ile ilgili bilgilere erişme, analiz etme, değerlendirme, doğru kararlar alarak uygulayabilme, sağlıklı beslenmeyi sürdürme, uygun miktarda sağlıklı besin seçme ve tüketme, gıda sisteminin işleyişini değerlendirme ve gıda güvencesinin sağlanması için gerekli olan istek, bilgi, beceri, tutum, davranış ve yeteneklerin bileşimidir. Toplumda, gıda ve beslenme okuryazarlığının öneminin anlaşılması ve yaygınlaşması sağlığın, iyilik halinin, sağııkı beslenme ve besin seçiminin geliştirilmesi ve sürdürülmesine katkı sağlayabilecektir. Bilgi, beceri ve davranış odaklı, kuramlara dayanan ve etkin eğitim yöntemlerinin kullanıldığı gıda ve beslenme okuryazarlığı girişimlerin planlanması ve uygulanmasında ilgili tüm paydaşların iş birliği içinde olmaları yararlı olacaktır.

Anahtar Kelimeler: Gıda ve beslenme, Okuryazarlık, Beslenme bilgisi, Beslenme eğitimi

\section{Food and Nutrition Literacy}

\begin{abstract}
In this research, the aim is to study the concept, definition, objective of nutrition literacy, required skills with some reference elements and also proposing a new definition for this term in order to contribute to the national literature. In this review study, secondary data which was obtained from the primary studies carried out in a similar subject was used. Nutrition literacy is the combination of access to, analysis, and evaluation of the information related to food and nutrition, making and implementation of good decisions, maintaining a healthy eating, choosing and consuming a proper amount of healthy food, and the motivation, knowledge, skill, attitude, behavior and abilities required for the evaluation of the motivation needed to ensure food security and the working of the food system. The recognition and dissemination food and nutrition literacy among the society will help the improvement of well-being, maintaining a healthy nutrition and choice of healthy food. It would be useful that all stakeholders are in cooperation in the planning and implementation of food literacy initiatives where effective, theorybased training methods focusing on knowledge, skill and behavior are used.
\end{abstract}

Key words: Food and nutrition, Literacy, Nutrition knowledge, Nutrition education

Giriş

Mevcut bilimsel kanıtlar, yetersiz ve aşırı beslenmenin çeşitli sağık sorunlarının oluşmasında önemli rol oynadığını göstermektedir (Anonim, 2004; Aihara ve
Minai, 2011). Kalp-damar hastalıkları, kanserler, kronik solunum yolu hastalıkları ve diyabetin bulaşıcı olmayan hastalıklar arasında öne çıktığı ve bu dört tip bulaşıcı olmayan hastalığın, düşük ve orta gelirli ülkelerin büyük çoğunluğunda görülen ilgili 
ölümlerde en büyük paya sahip oldukları bildirilmektedir. $\mathrm{Bu}$ hastalıkların, tütün kullanımı, sağlıksız beslenme, fiziksel hareketsizlik ve alkol kullanımından oluşan yaşam biçimiyle ilişkili ortak ve önlenebilir risk faktörleri ile bağlantılı olduğu kabul edilmektedir. Açlık, malnütrisyon, mikro besin öğelerinin yetersiz alımı da sağlığı tehdit eden etmenler arasında yer almaktadır. Yetersiz ve dengesiz beslenme ile ilişkili hastalıkların önlenmesi ve kontrolüne yönelik stratejilerde ortak risk faktörleriyle mücadele eden etkin girişimlere ihtiyaç vardır (Anonim, 2004). Bu girişimler arasında sürdürülebilir beslenme eğitimi, gıda ve beslenme okuryazarlığının geliştirilmesine yönelik çabalar önemli rol oynamaktadır. Küreselleşme sürecinde beklenen yaşam kalitesine ulaşmak için tüm bireylerin ve toplumun beslenme bilincini artırarak, sağlıklı beslenmenin yaşam biçimine dönüştürülmesi gerekmektedir (Pekcan, 2009).

Şanlıer ve ark. (2009) etkin ve sürekli verilecek beslenme eğitiminin sağlığın korunması ve geliştirilmesinde önemli rol oynadığını, her yaştaki insanın sağlığını tehdit eden sorunların ve uygulamaların önlenmesine, hatalı alışkanlıkların, davranışların değiştirilmesine sebep olacağını bildirmişlerdir. Beslenme davranışı diğer insan davranışları gibi çeşitli faktörlerden etkilenen oldukça karmaşık bir olgudur (Velardo, 2015) Gida ve beslenme konusunda sahip olunan bilgi, tutum, beceri ve davranışlar besin seçimi, tüketimini ve beslenme örüntüsünü etkileyebilmektedir.

Bilişim çağında, medya, sağlık, bilgi ve iletişim teknolojileri, ekoloji, finans, gıda ve beslenme gibi çeşitli konularda bireylerin bilgi, beceri, tutum ve davranışlara sahip olmalarının önemi ve gerekliliği dikkatleri bu konulardaki okuryazarlığa çekmektedir. Bu çağın, bir gereği olarak ortaya çıkan çeşitli okuryazarlık alanları arasında sağlık, ekoloji, medya, finans, gıda ve beslenme okuryazarlığı kavramları karşımıza sıklıkla çıkmaktadır (Nutbeam, 2000; CutterMackenzie ve Smith, 2003; Pérez Tornero ve Varis, 2010; Vidgen ve Gallegos, 2012, 2014; Brooks ve Begley, 2014; Cullen ve ark., 2015; Velardo, 2015; Von Gaudecker, 2015). Gıda ve beslenme okuryazarlığı, tüketicilerin besin, besin öğesi, besin grupları ve beslenme ile ilişkili çeşitli bilgileri anlayabilmeleri, eleştirel olarak değerlendirebilmeleri ve bu bilgileri sağlıklı besin seçimi ve tüketimine yönelik doğru kararlar alarak uygulamaları açısından önemlidir. Beslenme sağlık etkileşimi konusundaki bilinçlenme, gıda ürünlerinde ki artan çeşitlilik, ev dışında besin tüketimine yönelik alternatiflerin artması, gıda ve beslenme okuryazarlığını önemli bir konu haline getirmiştir (Keser ve Çıracıoğlu, 2015). Günlük yaşam içinde gıda ve beslenme ile ilgili çeşitli kararlar alınmaktadır. Bu kararlar alınırken, gıda ürünlerinin sağlık, besleyicilik, fiyat, lezzet, doğallık, doyuruculuk, tazelik, alışkanlık, kültürel uygunluk, kalite gibi çeşitli özellikleri göz önünde bulundurulmalıdır. Hangi tür yiyecekten, ne miktarda ve nereden satın alınacağı gibi pek çok kararı doğru biçimde alabilmek için gıda ve beslenme okuryazarı olmaya gereksinim duyulmaktadır.

Gıda ve beslenme okuryazarlığı konusunda yurt dışında yürütülen çalışma sayısında son yıllarda dikkat çeken bir artış olmakla birlikte, Türkiye'de bu konuda yürütülen bilimsel çalışma sayısı uluslararası literatür ile kıyaslandığında daha sınırlı sayıda kalmaktadır. Bu nedenle çalışmada; gıda ve beslenme okuryazarlığının önemi, tanımı, amacı ve gerekli beceriler ile işaret eden bazı 
unsurlar incelenerek ulusal literatüre katkı sağlanması amaçlanmıştır.

\section{Materyal ve Metot}

$\mathrm{Bu}$ derleme çalışma, ikincil verilere dayalı olarak hazırlanmıştır. Benzer konuda yapılmış birincil araştırmalardan ortaya çıkan daha önceden derlenmiş ikincil veriler çalışmanın veri kaynağını oluşturmuştur. Bu veriler, beslenme okuryazarlığı, gıda okuryazarlığı, okuryazarlık, literacy, nutrition literacy, food literacy gibi anahtar kelimeler kullanılarak elektronik bilimsel veri tabanları, basılı kitaplar, dergiler, tezler ve raporların yanı sıra uluslararası organizasyonların web sitelerinde yapılan taramalar sonucunda elde edilmiştir.

\section{Gıda ve Beslenme Okuryazarlığı Kavramı ve Tanımı}

Gıda ve beslenme okuryazarlığı teriminin, kavramsallaştırmanın önemi ve yararları vurgulanmakta (Velardo, 2015), dinamik bir yapıya sahip olduğu ifade edilmektedir. Vidgen ve Gallegos, (2014) ve Velardo, (2015) kavramsallaştırmanın bireysel, toplumsal, sosyal, kültürel, politik ve çevresel yararlarını vurgulamıştır. Gıda ve beslenme okuryazarlığı; gıda, beslenme ve sağlık; tarım, çevre ve ekoloji; sosyal kalkınma ve eşitlik gibi üç ana bilgi alanını kapsayan bir kavramdır (Bellotti, 2010). Bu kavram, beslenme dili (gıda ve beslenme konularındaki iletişimi), beslenme uygulamaları ve beslenme ekolojisi gibi bileşenlerden oluşur (Cimbaro, 2008). Block ve ark., (2005) bu bileşenleri, kavramsal bilgi, yöntemsel bilgi ve yetenek, firsat ve motivasyon olarak ifade etmişlerdir. Bu bileşenler, arasındaki karşııılı etkileşim, kültür, politika ve tarih gibi faktörlerin etkisiyle karmaşık ve dinamik bir sistem meydana getirirler. Bu sistemin en temel işlevi, herkes için sağlıklı beslenmeyi güvence altına alan uygulamaları yerine getirmek, bireylere gida sisteminde meydana gelen değişikliklere uyum sağlamaları konusunda yardım edebilmektir (Block ve ark., 2005; Cimbaro, 2008). Gıda okuryazarlığı kavramının, sürdürülebilir çevre, küresel gıda sistemi, sağlıkla ilgili davranışlar, yiyecek içecek kültürü ve becerileri gibi çeşitli öğeleri kapsadığı bildirilmiştir (Pendergast ve Dewhurst, 2012).

Gıda ve beslenme okuryazarlığı konusunda yapılan çalışmalar artmakla birlikte, bu kavram için tam olarak bir tanım birliği sağlanamamıştır. Zoellner ve ark., (2009) beslenme okuryazarlığını sağlık okuryazarlığına, benzer şekilde bireyin, temel beslenme bilgisine ulaşma, bu bilgiyi işleme ve anlama kapasitesi olarak tanımlamışlardır. Vidgen ve Gallegos, (2014) gıda okuryazarlığı tanımında, sağlıklı beslenmeyi sürdürerek, diyet dayanıklııı̆ının geliştirilmesi ve güçlendirilmesini böylece de diyet kalitesinin korunmasını vurgulamakta, besin alımının belirlenmesinde planlama, yönetme, seçme ve hazırlama gibi konularda bilgi, beceri ve davranışların etkileşimine dikkat çekmektedir.

Cimbaro (2008), beslenme okuryazarlığını gıda sistemleri ile biyolojik, sosyal ve ekolojik sistemlerin ilişkisi hakkında dili kullanarak bilgi üretmek ve bu bilgiyi topluma iletmek olarak ifade etmekte iken, Block ve ark., (2005) hem beslenme bilgilerini anlamayı, hemde bu bilgilerle uyumlu olarak hareket ederek, sağlıklı gıda ve beslenme hedeflerinin sürekli olarak geliştirilmesinin önemini vurgulamışlardır. Kolasa ve ark., (2001) ise, bireylerin gida ve beslenme hakkında temel bilgileri elde etme, işleme ve anlama yeteneği ve bu bilgileri uygun sağlık 
kararları alabilmeleri için kullanabilme yeterliliği olarak tanımlamışlardır.

Gıda okuryazarlığı başka bir tanımda ise, bireyin karmaşık gıda sistemine angaje olmak ve sisteme katılmak için, uygulamaları ve ilgisini yaşam boyunca geliştirebilme yeteneği ile çevresel, sosyal, ekonomik, kültürel ve siyasi bileşenleri dikkate alarak, bireysel sağlığa ve sürdürülebilir gıda sistemine erişimi desteklemek için, karar verme becerisi olarak ifade edilmiştir (Cullen ve ark., 2015). Bu tanımlardan da görüldüğü gibi bazı araştırmacılar (Cimbaro, 2008; Silk ve ark., 2008; Zoellner ve ark., 2009) beslenme okuryazarlığı, bazıları ise (Vidgen ve Gallegos 2014; Cullen ve ark., 2015) gıda okuryazarlığı terimini kullanmayı tercih etmişlerdir. Bu makalede, her iki terim birlikte ele alınarak bir tanım önerilmiştir. Önerilen bu tanıma göre; gıda ve beslenme okuryazarlığı gıda ve beslenme ile ilgili bilgilere erişme, analiz etme, değerlendirme, doğru kararlar alarak uygulayabilme; sağııkı beslenmeyi geliştirme, sürdürme, uygun miktarda sağlıklı besin seçme ve tüketme, gıda sisteminin işleyişini değerlendirme ile gıda güvencesinin sağlanması için gerekli olan, istek, bilgi, beceri, tutum, davranış ve yeteneklerin bileşimidir. Bu tanımda da görüldüğü gibi, gıda ve beslenme okuryazarlığı için bilginin yanı sıra istek, beceri, tutum, davranış ve yeteneklere de gereksinim olduğu vurgulanmaktadır. Nitekim, önceki çalışmalarda, sağ|ıklı beslenme, besin seçimi ve uygulamaları için tek başına gıda ve beslenme bilgisinin yeterli olmadığı (Contento, 2011; Velardo, 2015) motivasyona da ihtiyaç duyulduğu belirtilmiştir (Block ve ark., 2005).

\section{Gıda ve Beslenme Okuryazarlığının Amaçları ve İşaret Eden Bazı Unsurlar}

Toplumun her kesimini ilgilendiren bir gereksinim olan gida ve beslenme okuryazarlığını etkileyen değişkenlerden biride bu konuda sahip olunan becerilerdir. Değişik türdeki yazılı kaynakları, kayıtları kullanarak tanımlama, anlama, yorumlama, bir araya getirme, iletişim kurma ve hesap yapma yeteneklerini içeren okuryazarlık (Anonim, 2006) gida ve beslenme okuryazarlığının sağlanması açısından kritik bir öneme sahiptir. Okuryazarlık becerilerinin yanı sıra, bireylerin gıdalar ve beslenme hakkında karmaşık olan bilgiyi anlayabilmesi, eleştirel olarak değerlendirebilmesi, sağlıklı beslenme uygulamalarına dönüştürebilmesi için çeşitli becerilere gereksinim duyulmaktadır (Fordyce-Voorham, 2011; Vidgen ve Gallegos 2011; Pendergast ve Dewhurst 2012). Yiyecek ve içecek satın alırken çeşitli ölçütleri göz önünde bulundurma, ürün yetiştirme, besin seçme, hazırlama, pişirme, servis yapma gibi becerilere de sahip olmak gereklidir (Benn, 2014). Bununla birlikte, gida ve beslenme ile ilgili istatistik içeren bilgilerin, günlük tüketilmesi gereken miktarların, porsiyon ölçülerinin, besin etiketlerinde yer alan enerji ve besin değeri bilgilerinin anlaşılması için, matematiksel becerilere de gereksinim duyulduğu bildirilmiştir (Rothman ve ark., 2006; Misra, 2007; Huizinga ve ark., 2009; Speirs ve ark., 2012).

Gıda ve beslenme okuryazarları, beslenme uygulamaları için, kültür, politika ve tarih bakış açısını günlük beslenmenin diline (iletişimine), uygulamalarına ve ekolojisine uyarlayabilme becerisine ihtiyaç duyarlar. Bu bireyler, besin, besin öğesi, besin grupları, beslenme, beslenme ile ilişkili hastalıklar vb. gıda ve beslenme terminolojisi ile ilişkili terimlerin anlamlarını bilir, besin 
etiketleri, besin tabağı, besin piramidi gibi görsellerde ki mesajları doğru bir şekilde yorumlayabilirler. Ayrıca gıda üretim ve tüketim sistemlerinin biyolojik ve sosyal faktörlerle olan ilişkisi konusunda farkındalık geliştirebilirler. Gıda ürünleri ile ilgili ticari içerikli mesajları ayırt edebilirler (Cimbaro, 2008; Vidgen ve Gallegos 2012).

$\mathrm{Bu}$ tanımlardan da anlaşılabileceği gibi, gıda ve beslenme okuryazarlığı ile çeşitli amaçlara ulaşılması hedeflenmektedir. Gıda ve beslenme okuryazarlığının temel amaçları Çizelge 1'de verilmiştir (Cimbaro, 2008; Silk ve ark., 2008; Zoolner ve ark., 2009; Fordyce-Voorham, 2011; Pendergast ve Dewhurst, 2012; Benn, 2014; Brooks ve Begley, 2014; Vidgen ve Gallegos, 2014; Cullen ve ark., 2015; Velardo, 2015).

Çizelge 1. Gıda ve beslenme okuryazarlığının temel amaçları

Table 1. The main purpose of food and nutrition literacy

1. Gıda ve beslenme okuryazarlık düzeyini artırmak

2. Sağlıklı beslenmeye ilişkin motivasyon oluşturmak ve sürdürmek

3. Gıda ve beslenme bilgilerine ulaşabilmek ve etkili biçimde kullanabilmek

4. Sağlıklı besin seçimi ve tüketimine yardımcı olmak

5. Sağlıklı beslenmeyi sürdürebilmek için doğru davranışlarda bulunabilmek

6. Yiyecek ve içeceklerinin hazırlanması, pişirilmesi ve saklanması ile ilgili becerilere sahip olmak

7. Enerji ve besin öğesi gereksinimini doğru olarak belirleyebilmek

8. Gıda ve beslenme sorunlarına ilişkin farkındalık oluşturmak

9. Gıda ve beslenme sisteminin işleyişini değerlendirmek

10. Beslenmenin geleneksel, kültürel ve ekolojik boyutlarının farkına varılmasını sağlamak

11. Medyada yer alan mesajları eleştirel bir şekilde değerlendirebilmek

12. Besin etiketlerindeki enerji değeri ve besin içeriği gibi bilgileri kullanabilmek

13. Beslenme eğitiminin kalitesini artırmak ve yaygınlaştırmak

14. Gıda ve beslenme rehberlerindeki yazılı ve görsel mesajları yorumlayabilmek

15. Yayınları eleştirel ve kuramsal bakış açısı ile inceleyebilmek

Bireylerin gıda ve beslenme yönetim, seçim, hazırlama ve yemek yeme okuryazarlığına işaret eden ya da gösterge olabilecek çeşitli unsurlar üzerinde durulmaktadır. Vidgen ve Gallegos (2011, 2012, 2014) bu unsurları planlama ve olarak dört ana başlık, 11 madde altında toplamaktadır. Çizelge 2'de gıda ve beslenme okuryazarlığına işaret eden bazı unsurlar verilmiştir. 
Çizelge 2. Gıda ve beslenme okuryazarlığına işaret eden bazı unsurlar

Table 2. Pointing to some components of food and nutrition literacy

\begin{tabular}{|c|c|}
\hline \multicolumn{2}{|c|}{$\begin{array}{l}\text { Gıda ve beslenme okuryazarlığı olan bir birey... } \\
\text { Individuals with food and nutrition literacy... }\end{array}$} \\
\hline \multirow{3}{*}{ 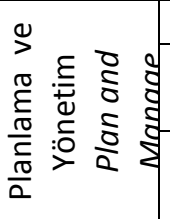 } & ...zaman ve finans kaynaklarını sağlıklı besin tüketimi için planlayabilir ve yönetebilir. \\
\hline & $\begin{array}{l}\text {...çevresel ya da mevcut beslenme düzeni içerisindeki değişiklikleri dikkate almadan çeşitli } \\
\text { kaynaklar aracılığıyla gıdaya erişebilir. }\end{array}$ \\
\hline & $\begin{array}{l}\text {...zaman, para, beceri, araç, gereç vb. kaynaklarla, gıdanın besleyiciliği, lezzeti ve açlığı } \\
\text { giderici özellikleri arasında dengeyi sağlayarak beslenme ile ilgili uygun kararlar alabilir. }\end{array}$ \\
\hline \multirow{3}{*}{ 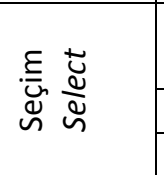 } & $\begin{array}{l}\text {...çeşitli kaynaklar aracılığıyla gıdaya ulaşmayı bilir ve bu kaynakların olumlu ve } \\
\text { olumsuz yönlerinin farkındadır. }\end{array}$ \\
\hline & ...gıda ürününün içeriğini, üretim yerini, depolama koşullarını ve nasıl tüketileceğini bilir. \\
\hline & gıdanın kalitesini sorgulayabilir. \\
\hline \multirow{2}{*}{ 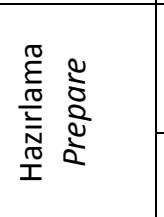 } & $\begin{array}{l}\text {...elindeki mevcut gıdalarla sağlıklı bir öğün düzenleyebilir. Yaygın olarak kullanılan } \\
\text { yiyeceklerle yemek hazırlayabilir, mutfak araç ve gereçlerini doğru kullanabilir. Yemek } \\
\text { tarifelerine ilişkin sahip olduğu bilgi ve becerilerini, yeni yemek tarifelerine uyarlayabilir. }\end{array}$ \\
\hline & $\begin{array}{l}\text {...yiyeceklerin hazırlanması, işlenmesi, pişirilmesi, saklanması ve gıda güvenliği konusundaki } \\
\text { temel prensipleri uygular. }\end{array}$ \\
\hline \multirow{3}{*}{ 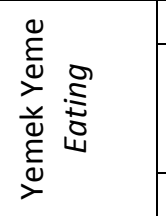 } & ...besinlerin, bireyin iyilik hali üzerindeki etkisini kavrayabilir. \\
\hline & $\begin{array}{l}\text {...ihtiyaç duyulan yeterli ve dengeli besin alımının sağlanabilmesi konusunda öz-farkındalık } \\
\text { gösterebilir. Sağlıklı yaşam için, yiyeceklerin içeriğini, uygun porsiyon miktarlarını, tüketim } \\
\text { sıklığını ve sınırlanması gereken yiyecekleri bilir. }\end{array}$ \\
\hline & ...yemek yemenin sosyal boyutunun farkındadır ve bu tür ortamlara katılabilir. \\
\hline
\end{tabular}

\section{Sonuçlar}

Gıda ve beslenme okuryazarlığı bireylerin gıda, beslenme, besin seçimi, besin tüketimi, sağlıklı beslenme, gıda güvencesi ve güvenliği gibi konularda doğru bilgi, tutum ve beceri sahibi olmalarını, bu konularda doğru kararlar almalarını ve uygun davranışlar göstermelerini içermektedir. Bu makale, gıda ve beslenme okuryazarlığı kavramı, tanımı, amaçları, gerekli beceriler, işaret eden unsurlar ve öneminin ortaya konulması ile sınırlıdır. Bu konuda yapılacak diğer çalışmalarda, gıda ve beslenme okuryazarlığının sınıflandırılması, boyutları, ölçüm yöntemleri gibi noktaların ele alınması, bu kavramın daha detaylı olarak incelenmesi ve anlaşılması açısından önem arz etmektedir.

Beslenme eğitiminin temel hedeflerinden biri, gıda ve beslenme okuryazarlığının yaygınlaştırılmasıdır. Sağlıklı beslenme davranışlarının geliştirilmesinde, gıda ve beslenme okuryazarlığı önemli bir rol oynamakla birlikte, bu durumu kolaylaştırıcı ve zorlaştırıcı çeşitli etmenler bulunmaktadır. $\mathrm{Bu}$ etmenlerin detaylı olarak incelenmesi ve çözüm yollarının ortaya konulmasında çok disiplinli, paydaş katılımlı yaklaşımların etkili olacağı düşünülmektedir. Gıda ve beslenme okuryazarlığı planlı eğitim programlarının yanı sıra informal eğitim aracılığıyla da ev, işyeri, sosyal alanlar gibi çeşitli ortamlarda, teknoloji ile bütünleşen stratejiler yoluyla ele alınabilir. Gıda ve beslenme okuryazarlığının geliştirmesi ve sürdürülmesinde uygun müdahale yöntemleri kullanılması önemlidir. $\mathrm{Bu}$ müdahalelerin planlanmasında, gıda ve beslenme okuryazarlığı ile medya, gıda, sağlık ve eğitim sistemi arasındaki ilişki dikkate alınmalıdır. Müdahalelerin verimliliği için paydaş ve ihtiyaç analizi, amaçların belirlenmesi, bilimsel kuram, yaklaşım ve modellerin temel alınması, uygun eğitim yöntemlerinin kullanılması, değerlendirme ve izleme çalışmalarının yapılması yararlı 
olacaktır. Müdahalelerde, bilginin yanı sıra beceri, tutum ve davranış değişikliğine yönelik girişimlerin daha etkili sonuçlar oluşturabileceği dikkate alınmalıdır. Gıda ve beslenme okuryazarlığının sağlık, sosyal, ekonomik ve çevresel yararları üzerinde ayrı ayrı durularak toplumsal bilinç oluşturulmaya yönelik etkili müdahale çalışmaları artırılmalı ve sürekliliği sağlanmalıdır.

\section{Kaynaklar}

Aihara, Y. ve Minai, J., 2011. Barriers and catalysts of nutrition literacy among elderly Japanese people. Health promotion international, 8: 1-11.

Anonim, 2004. World Health Organisation. Global strategy on diet, physical activity and health. Geneva: Fifty-seventh World Health Assembly http://www.who.int/dietphysicalactivity/s trategy/eb11344/strategy_english_web.p df. (acccess: 19.10.2015).

Anonim, 2006. Understandings of literacy. http://www.unesco.org/education/GMR2 006/full/chapt6_eng.pdf, pp.147-159. (acccess: 02.01.2016).

Bellotti, B., 2010. Food literacy: Reconnecting the city with the country. Agricultural Science. 22: 29-34.

Benn, J., 2014. Food, nutrition or cooking literacya review of concepts and competencies regarding food education. International journal of Home Economics, 17 (1): 13-35.

Block, L., Childers, T., Davis, B., Ebert, J., Kumanyika, L., van Ginkl-Bieshaar, M., 2005. From nutrients to nurturance: $A$ conceptual introduction to food wellbeing. Journal Public Policy Marketing, 30: 5-13.

Brooks, N. ve Begley, A., 2014. Adolescent food literacy programmes: A review of the literature. Nutrition and Dietetics, 71(3): 158-171.

Cimbaro, M.A., 2008. Nutrition literacy: Towards a new conception for home economics Education. The University of British Columbia, Vancouver.

Contento, R.I., 2011. Nutrition education linking research, theory and practice, Jones and Bartlett Publishers, Massachusetts.
Cullen, T., Hatch, J., Martin, W., Higgins, J.W., Sheppard, R., 2015. Food Literacy: Definition and Framework for Action. Canadian Journal of Dietetic Practice and Research, 76(3): 1-6.

Cutter-Mackenzie, A. ve Smith, R., 2003. Ecological literacy: The 'missing paradigm'in environmental education (part one). Environmental Education Research, 9(4): 497-524.

Fordyce-Voorham, S., 2011. Identification of essential food skills for skill-based healthful eating programs in secondary schools. Journal of Nutrition Education and Behavior, 43(2): 116-122.

Huizinga, M.M., Carlisle, A.J., Cavanaugh, K.L., Davis, D.L., Gregory, R.P., Schlundt, D.G., 2009. Literacy, numeracy, and portion-size estimation skills. American Journal of Preventive Medicine, 36: 324-328.,

Keser, A. ve Çıracıoğlu, E.D., 2015. Sağlık ve Beslenme Okuryazarlığı. Sağlık Okuryazarlığı, (Ed.) Yıldırım, $F$ ve Keser, A., Ankara Üniversitesi Yayın No:455, Ankara Üniversitesi Basımevi, Ankara, 39-59s.

Kolasa, K.M., Peery, A., Harris, Shovelin, K., 2001. Food literacy partners program: a strategy to increase community food literacy. Topics in Clinical Nutrition. 16 (4): 1.

Misra, R., 2007. Knowledge, attitudes, and label use among college students. Journal of the American Dietetic Association, 107: 21302134.

Nutbeam, D., 2000. Health literacy as a public health goal: a challenge for contemporary health education and communication strategies into the 21st century. Health Promotion International, 15(3), 259-267.

Pekcan, G., 2009. Türkiye'de Beslenme ve Sağıık Durumu. Hacettepe Beslenme ve Diyetetik Günleri II. Mezuniyet Sonrası Eğitim Kursu, 19-20 Haziran, Ankara.

Pendergast, D. ve Dewhurst, Y., 2012. Home Economics and food literacy: An international investigation, International Journal of Home Economics, 5(2): 245-263.

Pérez Tornero, J.M. ve Varis, T., 2010. Media Literacy and new humanism. UNESCO Institute for Information Technologies in Education, Russian Federation. 136p.

Rothman, R.L., Housam, R., Weiss, H., Davis, D., Gregory, R., Gebretsadik, T., Shintani, A., Elasy, T.A., 2006. Patient understanding of food labels: the role of literacy and 
numeracy. American Journal of Preventive Medicine, 31(5): 391-398.

Silk, K.J., Sherry, J., Winn, B., Keesecker, N., Horodynski, M.A., Sayir, A., 2008. Increasing nutrition literacy: testing the effectiveness of print, web site, and game modalities. Journal of Nutrition Education and Behavior, 40: 3-10.

Speirs, K.E., Messina, L.A., Munger, A.L., Grutzmacher, S.K., 2012. Health literacy and nutrition behaviors among lowIncome adults. Journal of Health Care for the Poor and Underserved, 23(3): 10821091.

Şanlıer, N., Konaklıŏlu, E., Güçer, E., 2009. Gençlerin beslenme bilgi alışkanlık ve davranışları ile beden kütle indeksleri arasındaki ilişki, G.Ü. Gazi Eğitim Fakültesi Dergisi, 29(2): 333-352.

Velardo, S., 2015. The nuances of health literacy, nutrition literacy, and food literacy. Journal of Nutrition Education Behavior, 47: 385-389.

Vidgen, H.A. ve Gallegos, D., 2011. What is food literacy and does it influence what we eat: a study of Australian food experts. Queensland University of Technology, Brisbane, Queensland, Australia.

Vidgen, H.A. ve Gallegos, D., 2012. Defining food literacy, its components, development and relationship to food intake: A case study of young people and disadvantage. Queensland University of Technology Brisbane, Queensland, Australia.

Vidgen, H.A. ve Gallegos, D., 2014. Defining food literacy and its components. Appetite, 76(1): 50-59.

Von Gaudecker, H.M., 2015. How does household portfolio diversification vary with financial literacy and financial advice? The Journal of Finance, 70(2): 489-507.

Zoellner, J., Connell, C., Bounds, W., Crook, L., Yadrick, K., 2009. Nutrition literacy status and preferred nutrition communication channels among adults in the lower Mississippi delta. Preventing Chronic Disease, 6: A128. 